\title{
Mechanistic Force Modeling for Broaching Process
}

\author{
Raghavendra Kamath Cholpadi ${ }^{1}$ and Appu Kuttan ${ }^{2}$ \\ ${ }^{1}$ Mechanical \& Manufacturing Engineering Department, MIT, Manipal, Karnataka 576104, India \\ ${ }^{2}$ Mechanical Engineering Department, NITK, Surathkal, Karnataka 575025, India
}

Correspondence should be addressed to Raghavendra Kamath Cholpadi; crkamath77@gmail.com

Received 29 September 2013; Accepted 2 January 2014; Published 17 February 2014

Academic Editor: Tuğrul Özel

Copyright (C) 2014 R. Kamath Cholpadi and A. Kuttan. This is an open access article distributed under the Creative Commons Attribution License, which permits unrestricted use, distribution, and reproduction in any medium, provided the original work is properly cited.

\begin{abstract}
There is a demand for mechanistic force model that can predict and simulate the broaching process. In this paper, an attempt has been made for mechanistic force modeling of the broaching operation and experimental corroboration with the simulated result. The stiffness and damping coefficients for dynamic model are computed from the natural frequency of the broaching system and actual damped natural frequency has been obtained experimentally. Experimental work has been carried to compute the dynamic model parameters such as mass, stiffness, and damping coefficients. The simulated dynamic forces are illustrated graphically and are closely in agreement with the results obtained through manual broaching process.
\end{abstract}

\section{Introduction}

The broaching process may be used to generate irregular internal and external part features, and therefore has many potential industrial applications. Slotting, spline cutting, and production of internal helical gears are the major applications in which the broaching process has been used $[1,2]$. One of the advantages of broaching over other competitive processes is its higher productivity. However, since the material removal rates are relatively high for broaching, the cutting forces are also high. As a result there will be large deflection which gives rise to high surface errors. Therefore, careful attention must be directed towards the design of the broach geometry and the selection of process conditions [3-5].

Broach teeth usually are divided into three separate sections along the length of the tool. These include roughing teeth, semifinishing teeth, and finishing teeth. The first roughing tooth is proportionately the smallest tooth on the tool. The subsequent teeth progressively increase in size up to and including the first finishing tooth. The difference in height between each tooth, or tooth rise, usually is greater along the roughing section, less along the semifinishing section. All finishing teeth of a broach are almost the same size with microns difference [3-5].

Historically, broaches have been designed based on experience or through trial and error. As more emphasis is placed on part accuracy and precision, it becomes less likely that satisfactory broach geometry can be designed based on experience [6-8]. Additionally, as manufacturers struggle to reduce costs and nonproductive time, it becomes clear that trial and error approaches to tooling design will not be satisfactory. To design a broach early in the life cycle of a product, a model for how a broach will perform during the operation would be extremely advantageous, for a given raw part and broach geometries. The mechanistic modeling of cutting forces in broaching process is important for the design of broach tool.

Maximum force on an internal pull broach is a function of minimum cross section of the tool and yield point of tool material $[9,10]$. The allowable pulling force used to be determined empirically in earlier days [3,4]. Russian scientists have given empirical relation to determine the maximum allowable broaching force in broach tool which can withstand without damage. They specified a broaching constant whose value is a function of workpiece material. The cutting force is dependent on width of cut, depth, or rise per tooth, and so forth $[5,11]$. Many mechanistic models for systems in machining are described in the literature; these models are however used in turning and boring operation [5, 6]. Models have been developed for multipoint tool process such as end milling and face milling [12-14]. 
In this paper an attempt has been made to investigate mechanistic model for the cutting force in rectangular slotting operation; the static and dynamic forces are modeled during the broaching operation. For static model the relevant equations are formulated to compute the forces considering chip thickness area and proportionality constant. The proportionality constant is determined using a specific energy constant obtained experimentally. Dynamic forces are due to the variations of chip thickness during broaching process. Dynamic equations are formulated and parameters of the dynamic equations are computed using theoretically obtained natural frequency and damped natural frequency obtained through experiment. Static and dynamic forces obtained through the model are verified experimentally. To compute the chip load area, the broach coordinates are measured using toolmakers microscope and broach profile configuration is obtained using AutoCAD. Axial, radial, and tangential forces acting on the broach are simulated and presented graphically.

\section{Mechanistic Modeling}

2.1. Specific Cutting Energy Constant Computation. In the mechanistic modeling, for any machining process the basic equations that relates the $F_{x}, F_{y}$, and $F_{z}$ to the chip cross sectional area are given by $[15,16]$

$$
\begin{aligned}
& F_{x}=K_{x} A_{c}, \\
& F_{y}=K_{y} A_{c}, \\
& F_{z}=K_{z} A_{c},
\end{aligned}
$$

where $F_{x}, F_{y}$, and $F_{z}$ are the three dimensional forces acting on the tool tip.

The specific cutting energy constant depends on $t_{c}, v_{c}$, and $\gamma_{a}$ of the cutting tool. Mathematically [12],

$$
\begin{aligned}
\log K_{x}= & a_{0}+a_{1} \log t_{c}+a_{2} \log v_{c} \\
& +a_{3} \log t_{c} \log v_{c}+a_{4} \log \gamma_{a}, \\
\log K_{y}= & b_{0}+b_{1} \log t_{c}+b_{2} \log v_{c}+b_{3} \log t_{c} \log v_{c} \\
& +b_{4} \log \gamma_{a} \\
\log K_{z}= & c_{0}+c_{1} \log t_{c}+c_{2} \log v_{c}+c_{3} \log t_{c} \log v_{c}+c_{4} \log \gamma_{a} .
\end{aligned}
$$

The coefficients $a_{i}$ 's, $b_{i}$ 's, and $c_{i}$ 's $(i=1,2,3,4)$ depend upon the tool and work piece material and range of cutting speed and chip thickness and they are independent of the machining process. Usually these constants are determined from calibration test for a given tool and work piece combination and given range of cutting conditions [12]. Keeping the rake angle and the velocity of the tool movement as constant corresponding to the broach, (2) reduces to

$$
\begin{aligned}
& \log K_{x}=a_{0}+a_{1} \log t_{c}, \\
& \log K_{y}=b_{0}+b_{1} \log t_{c}, \\
& \log K_{z}=c_{0}+c_{1} \log t_{c} .
\end{aligned}
$$

The values of specific cutting energy constants can be determined using a simple calibration experiment [17-19]. The experiments were conducted for shaping operation and specific cutting energy constants are determined.

2.2. Experimental Investigation. Experiments were conducted on three work materials namely mild steel, aluminium, and cast iron and was repeated three times for a cutter with varying different depth of work material. Initially, three experiments were conducted on each set of processes. The first set of experiments was used to ascertain which tool and cut geometry's variables affect the proportionality constants. The second set of experiments were used to develop adequate model for proportionality constant based on the important tool and cut geometry variables, determined from first set of experiments. Third experiment was used to evaluate the specific cutting energy constants and hence the proportionality constants for mechanistic modeling.

Chip thickness area for the calibration purpose is measured from the chip curl. The volume of the chip is measured using water displacement method. After that, the chip curl is heated and elongated. The width of the chip $b$ and length $\ell$ are measured using micrometer and vernier caliper, respectively. Then, the actual chip thickness $t_{c}$ is obtained by volume divided by the product of length and width; that is, $t_{c}=$ $v / b \ell$ where " $v$ " is the volume of chip curl. Knowing the chip thickness " $t_{c}$ " and width " $b$ " of the cut, the chip load area can be computed as the product of $t_{c}$ and $b$.

2.3. Results and Discussions. Figures 1(a), 1(b), and 1(c) illustrate the cutting force versus chip thickness during shaping operation for the mild steel material. In the plot, $x$-axis indicates the logarithm value of chip thickness $t_{c}$ and $y$ axis is the logarithm of the cutting forces along $x, y$, and $z$ directions, marked as $F_{x}, F_{y}$, and $F_{z}$, respectively in Newton. The chip thickness is corresponding to depth of cut which varied from $0.04 \mathrm{~mm}$ to $0.16 \mathrm{~mm}$. The calibration test is performed for small depth of cut to avoid the error due to impulsive cutting forces coming on the workpiece at higher depth of cut. A linear curve fitting is made using Matlab software to determine the specific energy constants. Tool geometries were considered the same as the broaching tool. Hence, the variation in specific cutting energy constants is not considered for the rake angle variation in the tool.

Negative slope linear curves are obtained and the coefficients of the linear curve fitting give the specific cutting energy constants. The proportionality constants $K_{x}, K_{y}$, and $K_{z}$ are determined using (3). Tables 1 and 2 give the values of specific cutting energy constants and proportionality constants for materials mild steel, aluminium, and cast iron, respectively.

\section{Static Model}

Accurate modeling of cutting force is required to predict the vibration, surface quality, and stability of the machining process [20]. In the static force model, axial cutting force, $F_{x}$ during broaching is acting on the tooth as the product 


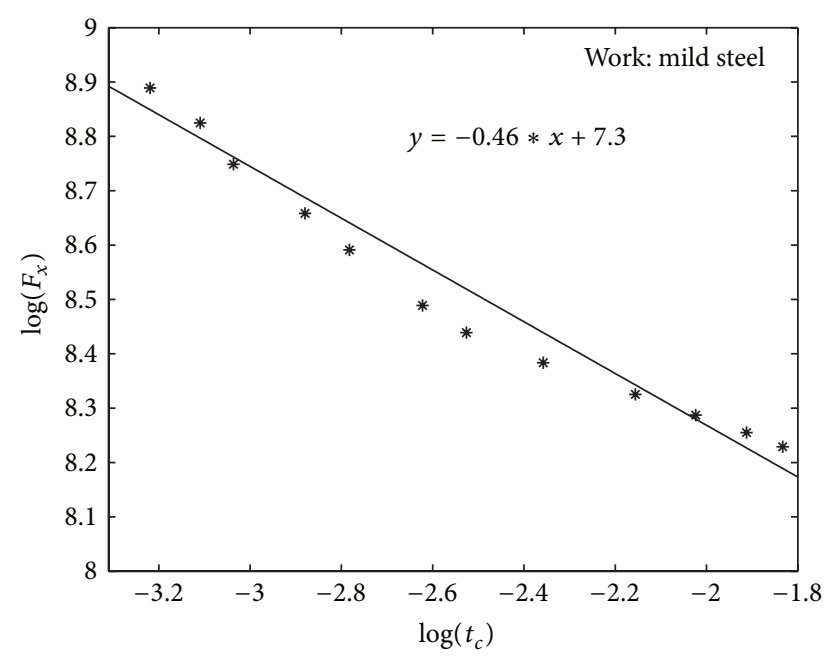

(a) Graph for determining $a_{0}$ and $a_{1}$

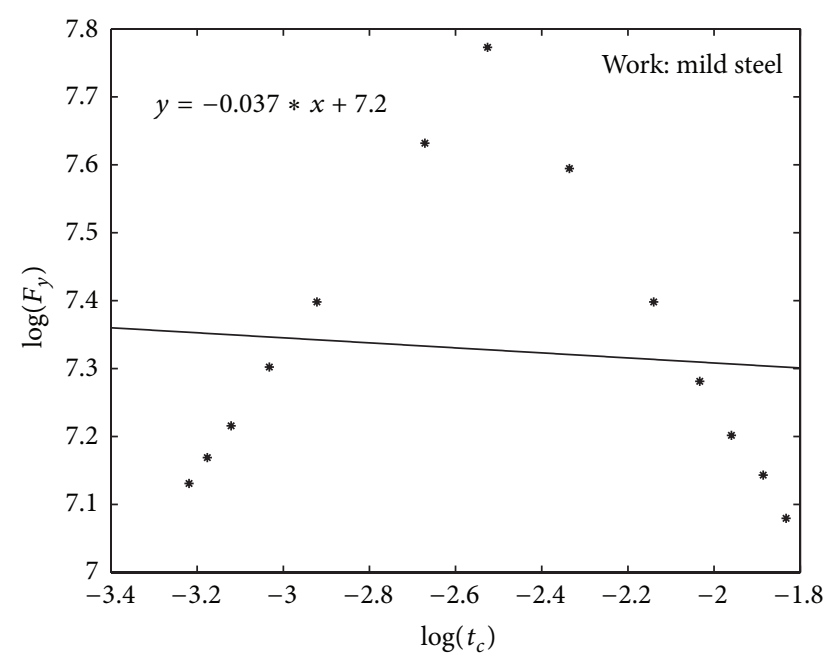

(b) Graph for determining $b_{0}$ and $b_{1}$

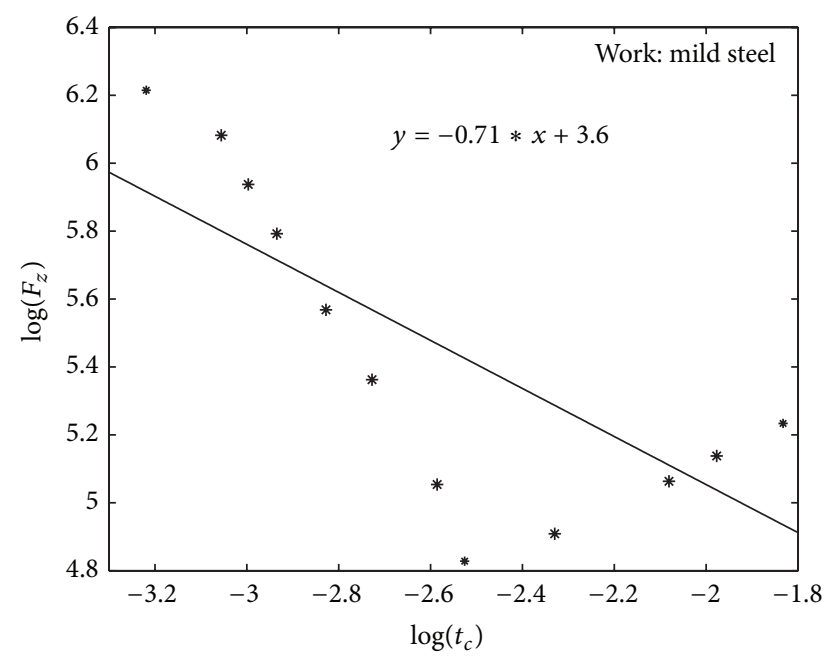

(c) Graph for determining $c_{0}$ and $c_{1}$

FIGURE 1: Specific cutting energy constants for mild steel obtained during shaping operation.
TABLE 1: Specific cutting energy constants during shaping process.

\begin{tabular}{lcccccc}
\hline Material & $a_{0}$ & $a_{1}$ & $b_{0}$ & $b_{1}$ & $c_{0}$ & $c_{1}$ \\
\hline Mild steel & 7.3 & -0.46 & 7.2 & -0.037 & 3.6 & -0.71 \\
Aluminium & 7.4 & -0.39 & 5.0 & -0.68 & 2.1 & -1.2 \\
Cast iron & 7.3 & -0.29 & 5.9 & -0.31 & 2.3 & -1.0 \\
\hline
\end{tabular}

TABLE 2: Proportionality constants for broaching process.

\begin{tabular}{lccc}
\hline Material & $K_{x}\left(\mathrm{~N} / \mathrm{mm}^{2}\right)$ & $K_{y}\left(\mathrm{~N} / \mathrm{mm}^{2}\right)$ & $K_{z}\left(\mathrm{~N} / \mathrm{mm}^{2}\right)$ \\
\hline Mild steel & 5732.3 & 1654.0 & 307.1 \\
Aluminium & 5370.0 & 1088.0 & 279.4 \\
Cast iron & 3562.0 & 924.4 & 199.5 \\
\hline
\end{tabular}

of chip cross section area $A_{c}$ and a proportionality constant, $K_{x}$. Similarly normal force $F_{y}$ acting along the cutting edge is obtained by multiplying the chip cross section area with proportionality constant $K_{y}$ and lateral force $F_{z}$ is similarly obtained by multiplying chip cross section area by proportionality constant, $K_{z}$. The values of $K_{x}, K_{y}$, and $K_{z}$ are determined by simple calibration test using the shaping operation.

A static analysis calculates the effects of steady loading conditions on a structure, while ignoring inertia and damping effects, such as those caused by time-varying loads. A static analysis can, however, include steady inertia loads (such as gravity and rotational velocity) and time-varying loads that can be approximated as static equivalent loads [21, 22].

3.1. Chip Load Area Measurement. Tool maker's microscope is used to get the coordinates of tooth profile. AutoCAD drawing of the broaching tool is drawn to get the dimensions of the tool profile and to get chip load area. Figure 2 shows the profile of one tooth and Figure 3 shows the AutoCAD drawing of the complete broaching tool.

From the AutoCAD drawing, pitch $=6.98 \mathrm{~mm}$, rake angle $=3^{\circ}$, rise per tooth $=0.05 \mathrm{~mm}$, width $=8 \mathrm{~mm}$. Hence chip load area $=$ width $\times$ rise per tooth $=0.4 \mathrm{~mm}^{2}$.

\subsection{Simulation of Static Cutting Force Model Using Matlab} Program. A MatLab program has been written to simulate the static force model. The simulation results have been plotted as shown in Figures 4(a) and 4(b) for different depth of the workpiece. When the workpiece depth is very small it gives a periodic variation in the cutting force in axial direction. The cutting forces in radial and transverse direction are negligibly small. As the depth of the workpiece increases the cutting force progressively increases until reaching a steady state force when all the teeth are engaged in the workpiece. Then, suddenly the cutting force falls as the broach disengages with the workpiece. Experiment was repeated for different workpieces of depths $5 \mathrm{~mm}$ and $40 \mathrm{~mm}$ and simulated pattern of the cutting force was obtained as in Figures 4(a) and 4(b). Experiment was conducted for mild steel workpiece. Axial cutting force proportionally increases as the depth of the material increases. When all the cutting 


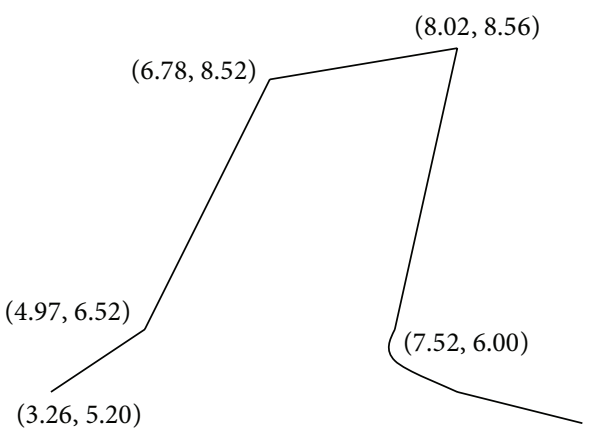

FIGURE 2: Broach tooth profile obtained from Toolmaker's microscope and AutoCAD drawing.

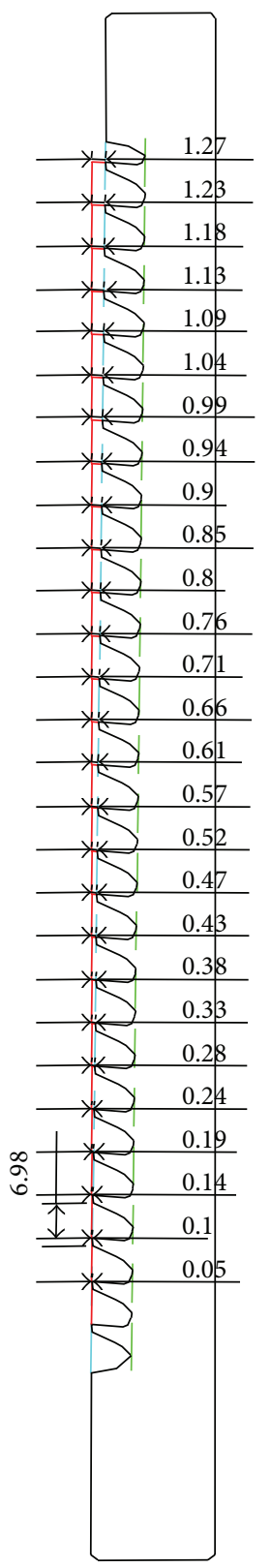

FIgURE 3: AutoCAD drawing of broach tool. tips are engaged in the workpiece the cutting force required is stable at a steady state cutting conditions.

For higher depth of the workpiece, initial increase in the cutting forces, there is a step by step increase in the cutting forces. This clearly indicates the engagement of the cutting tooth as the broach goes inside the workpiece. When the depth of the workpiece is less than $5 \mathrm{~mm}$, the nature of the cutting force is periodic and frequency of the spectrum obtained from the graph shows maximum cutting force at $40 \mathrm{~Hz}$. This indicates that cutting force variation mainly depends upon the chip thickness variation since there is no peak values observed at higher frequency. The feed rate of the broach is $10 \mathrm{~mm} / \mathrm{second}$.

\section{Development of Dynamic Force Model}

The broaching operation uses only two dimensional models and cutting force in lateral direction is negligibly small and not relevant. This is because axial force is more predominant and lateral force is very small in comparison. Figure 5 shows the cutting force direction on a broaching tool.

Broaching is analyzed as orthogonal cutting because the chip velocity is orthogonal to the cutting edge in the slotting operation. Even though all the cutting processes are oblique cutting, in the case of broaching, the cutting happens to be in depth-wise, hence, the assumption of orthogonal cutting is valid [23-25].

For determining the dynamic cutting forces, the two degrees of freedom vibratory system is considered and the model parameters of the machine tool structural system have been determined. By assuming that worktable and spindle head of the machine tool are rigid bodies, the vibratory system of the workpiece and tool in a one directional reference system was modeled as two degrees of freedom system as shown in Figure 6. The parameters of this system were determined from the theoretical natural frequencies and damped natural frequency corresponding to frequency obtained from the actual cutting system.

Assuming tool and workpiece as a rigid body, the system can be modeled as

$$
[M] \ddot{X}+[C] \dot{X}+[K] X=[F]
$$

where $X=\left\{\begin{array}{llll}x_{1} & x_{2} & y_{1} & y_{2}\end{array}\right\}^{T}$ is the relative displacement vector between tool and workpiece and $F=\left\{\begin{array}{llll}F_{x} & 0 & F_{y} & 0\end{array}\right\}^{T}$ is the force vector; $[M]$ is the mass matrix which depends on tool and workpiece and $[C]$ is the damping coefficient which depends on cutting feed and speed between the tool and workpiece and $[K]$ is the stiffness matrix connecting the tool and workpiece.

The values for $[M],[C]$, and $[K]$ are:

$$
[M]=\left[\begin{array}{cccc}
M_{1} & 0 & 0 & 0 \\
0 & M_{2} & 0 & 0 \\
0 & 0 & M_{1} & 0 \\
0 & 0 & 0 & M_{2}
\end{array}\right]
$$




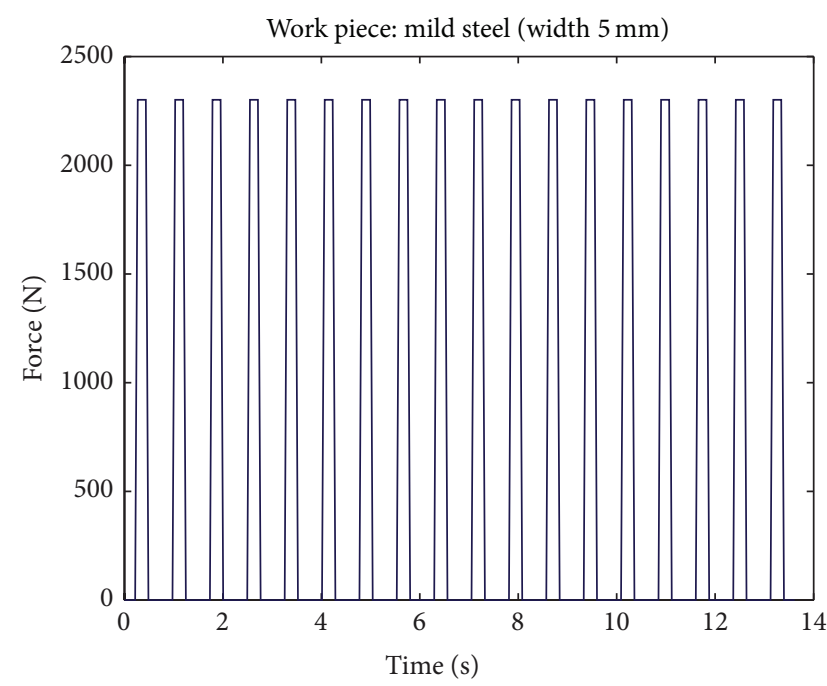

(a) Static axial cutting force on mild steel (depth $5 \mathrm{~mm}$ )

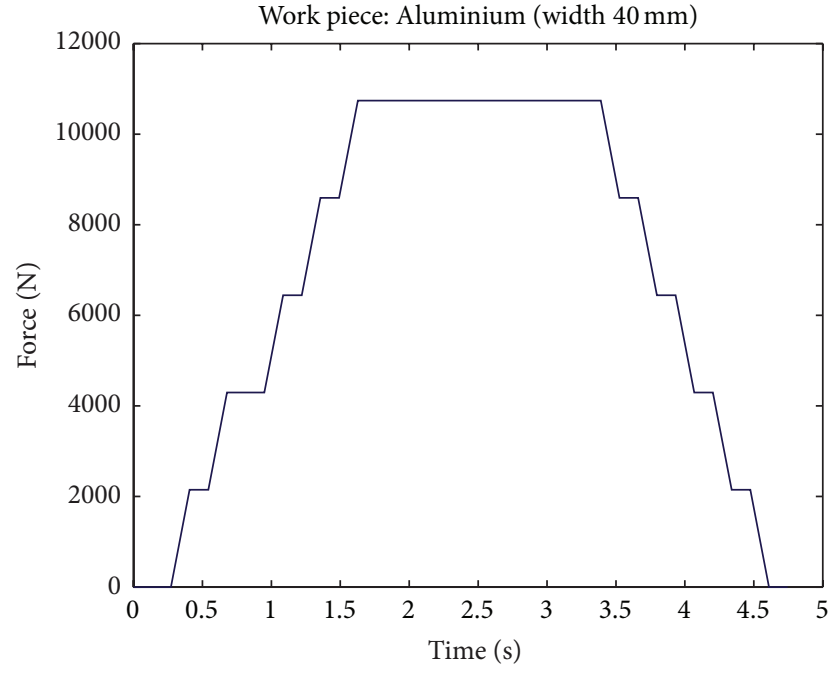

(b) Static axial cutting force on mild steel (depth $40 \mathrm{~mm}$ )

FIGURE 4: Static force variation for mild steel workpiece of depth from $5 \mathrm{~mm}$ to $40 \mathrm{~mm}$.
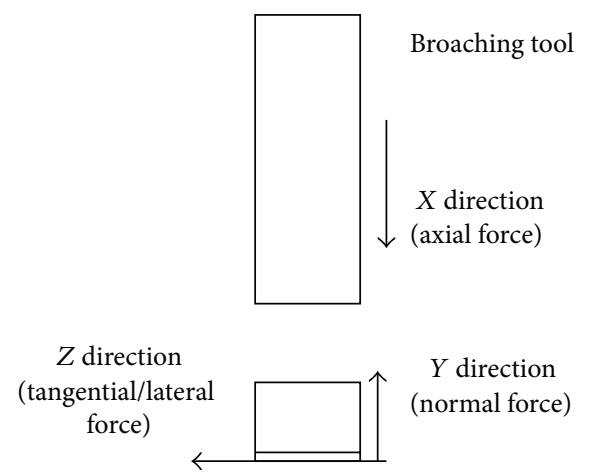

FIGURE 5: Schematic diagram showing direction of the cutting forces acting on a broach.

$$
\begin{aligned}
& {[C]=\left[\begin{array}{cccc}
C_{11}+C_{12} & -C_{12} & 0 & 0 \\
-C_{12} & C_{12} & 0 & 0 \\
0 & 0 & C_{21}+C_{22} & -C_{22} \\
0 & 0 & -C_{22} & C_{22}
\end{array}\right],} \\
& {[K]=\left[\begin{array}{cccc}
K_{11}+K_{12} & -K_{12} & 0 & 0 \\
-K_{12} & K_{12} & 0 & 0 \\
0 & 0 & K_{21}+K_{22} & -K_{22} \\
0 & 0 & -K_{22} & K_{22}
\end{array}\right] .}
\end{aligned}
$$

Using (4), deflections $X(t)$ have been computed using Wilson theta method $[12,24]$. To solve (4), for the first iteration static forces $F_{x}$ and $F_{y}$ are used in the force vector $F$. Deflections $X(t)$ were then computed and dynamic forces $d F_{x}$ have then solved. In the next iteration, the computed dynamic forces were used to solve (4). The procedure was continued until it converged.

In Wilson Theta method, basic assumption is made such that the acceleration varies linearly not only with time for a period but also over an extended time period or step. The instantaneous dynamic force component $d F_{x}(t, \varphi)$ caused by total chip thickness variation can be expressed as

$$
d F_{x}(t, \phi)=K_{x} U(t, \phi) D_{i}(t, \phi),
$$

where $U(t, \phi)$ is the resultant chip thickness variation and it is given by the equation

$$
U(t, \phi)=U_{x}(t, \phi)=\left[X_{0}(t, \phi)-X_{I}(t, \phi)\right],
$$

where

$$
X_{1}(t, \phi)=X_{1}(t, \phi)-X_{2}(t, \phi) \text {. }
$$

$X_{1}$ and $X_{2}$ represent the displacements of the tool and work piece corresponding to broach rotational angle, $\phi$, respectively. Instantaneous outer modulation $X_{0}(t, \phi)$ can be obtained by delaying the inner modulation by the time lag of one tooth of the broach as

$$
X_{0}(t, \phi)=X_{I}\left[t,\left(\phi-\frac{2 \pi N}{60 Z_{n}}\right)\right] .
$$

Since keyway broach is used in the slotting operation, $\phi$ is taken as zero and $D_{i}(t, \phi)$ is the instantaneous depth of cut.

4.1. Computation of Dynamic Force Model Parameters. To determine the dynamic force, using (1), mass matrix $[M]$, damping coefficient matrix $[C]$, and stiffness matrix $[K]$ have to be determined. The parameters for the dynamic system were determined form experimentally obtained force spectrum and natural frequency of the cutter. Two directional damped natural frequency $\omega_{d}$ has been obtained experimentally during actual cutting conditions. Knowing the natural frequency and damped natural frequency, damping ratio was computed. Knowing the mass and stiffness of the broach tool, damping coefficient $C$ is computed and the computed values are shown in Table 3. 


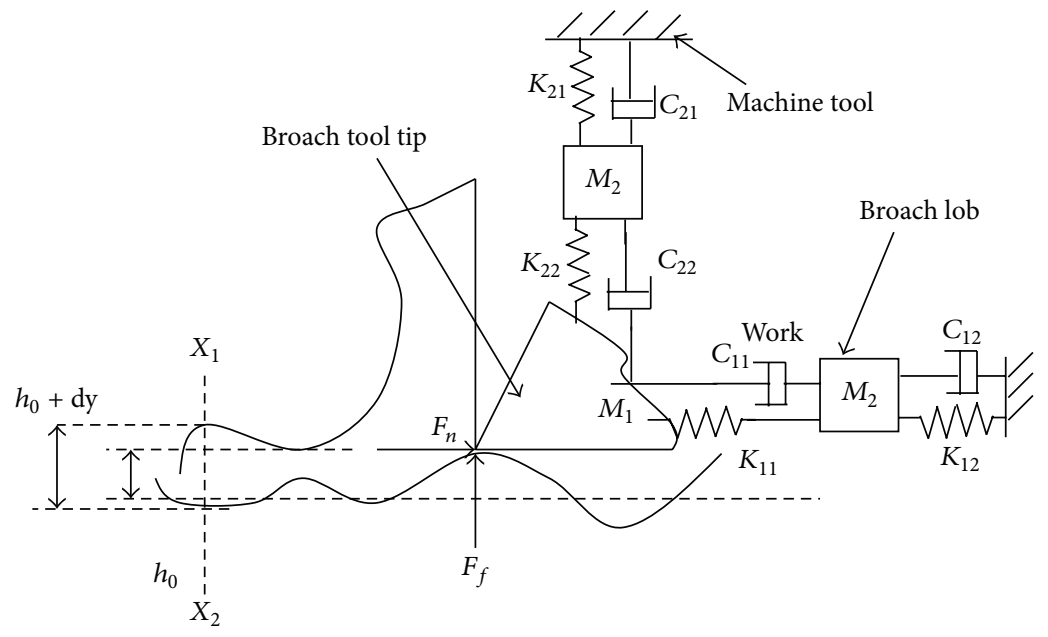

FIGURE 6: Dynamic force model for broaching.

TABLE 3: Damping coefficients and stiffness parameters for dynamic model.

\begin{tabular}{lccccc}
\hline Damping coefficients & $\begin{array}{c}\text { Value } \\
(\mathrm{N} / \mathrm{mm} / \mathrm{sec})\end{array}$ & Stiffness parameters & $\begin{array}{c}\text { Value } \\
(\mathrm{N} / \mathrm{mm})\end{array}$ \\
\hline$c_{11}$ & $c_{21}$ & 140 & $k_{11}$ & $k_{12}$ & $7.0 \times 10^{6}$ \\
$c_{12}$ & $c_{22}$ & 60 & $k_{21}$ & $k_{22}$ & $6.0 \times 10^{6}$ \\
\hline
\end{tabular}

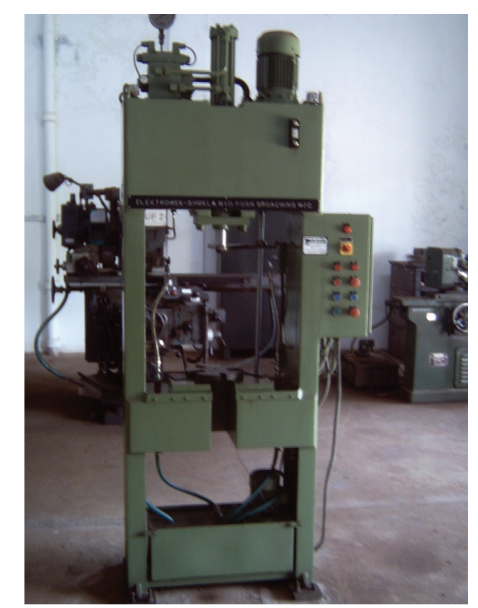

Figure 7: Photograph of a Push type broaching machine.

The computed mass, stiffness, and damping coefficient matrix are

$$
\begin{aligned}
& {[M]=\left[\begin{array}{cccc}
0.35 & 0 & 0 & 0 \\
0 & 0.116 & 0 & 0 \\
0 & 0 & 0.35 & 0 \\
0 & 0 & 0 & 0.116
\end{array}\right],} \\
& {[K]=10^{6}\left[\begin{array}{cccc}
23 & -9 & 0 & 0 \\
-9 & 23 & 0 & 0 \\
0 & 0 & 17 & -6 \\
0 & 0 & -6 & 15
\end{array}\right]}
\end{aligned}
$$

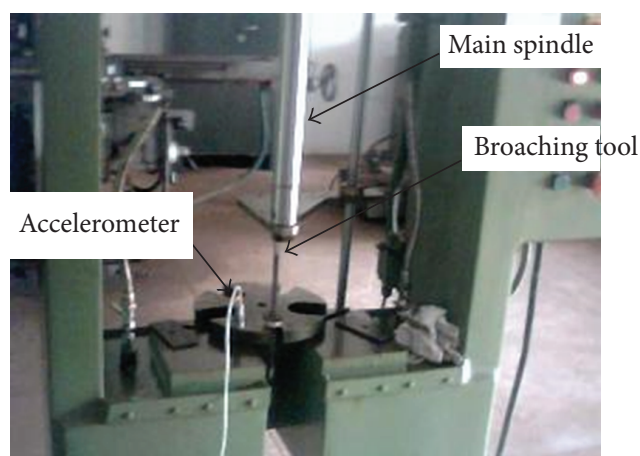

FIGURE 8: Photograph indicating the position of an accelerometer.

$$
[C]=\left[\begin{array}{cccc}
200 & -60 & 0 & 0 \\
-60 & 150 & 0 & 0 \\
0 & 0 & 200 & -50 \\
0 & 0 & -50 & 50
\end{array}\right]
$$

\section{Experimental Setup}

The experimental setup includes a push type broaching machine as shown in Figure 7 which was used for measuring the cutting force in three directions, keyway broach, Kistler accelerometer, and data acquisition system. The data acquisition system consists of hardware unit and an application programming interface. The real-time analog signals obtained from the accelerometer are sent to the hardware unit. The hardware unit performs the conditioning like amplification and filtering of the signals to increase the signal-to-noise ratio. This conditioned analog signal is sent through the proper cables to a data acquisition card which has electronic integrated circuit to convert the analog signal into the digital counterpart and sends the signal to the computer for further processing where it can store 1000 characters per second data in the computer. The program in the personal computer (PC) written using the Application Programming Interface (API) software performs the relevant operations on the input signal 


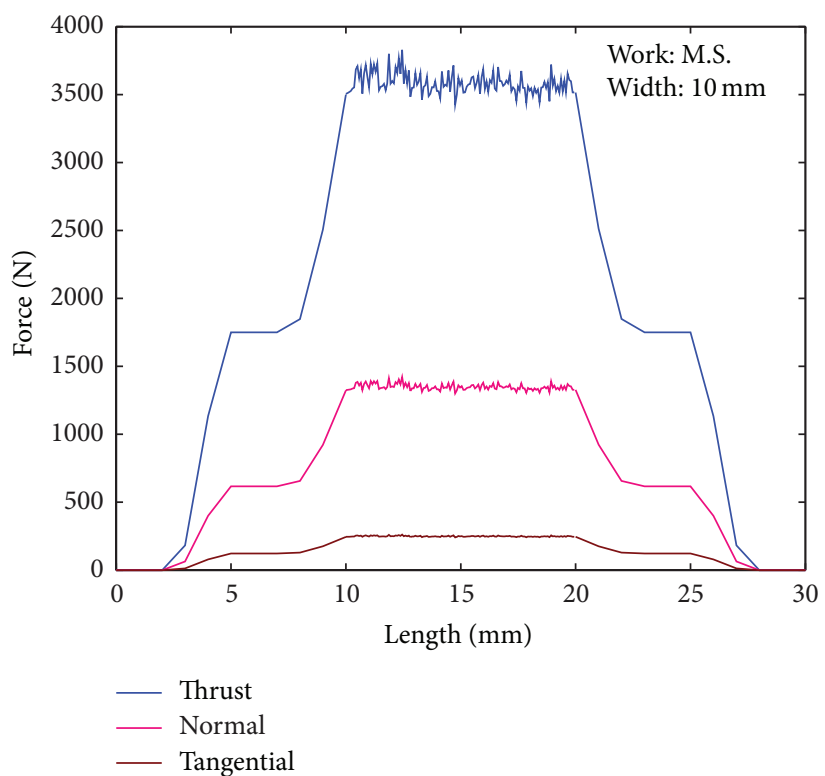

(a) Cutting forces for $10 \mathrm{~mm}$ depth

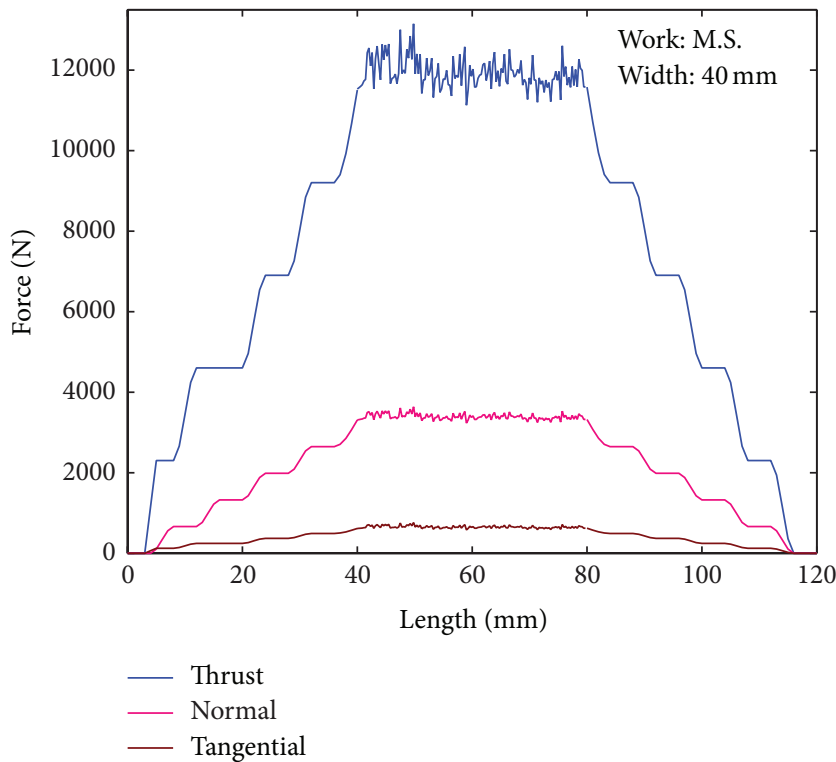

(b) Cutting forces for $40 \mathrm{~mm}$ depth

Figure 9: Measured force values for mild steel work material of $10 \mathrm{~mm}$ and $40 \mathrm{~mm}$ depth.

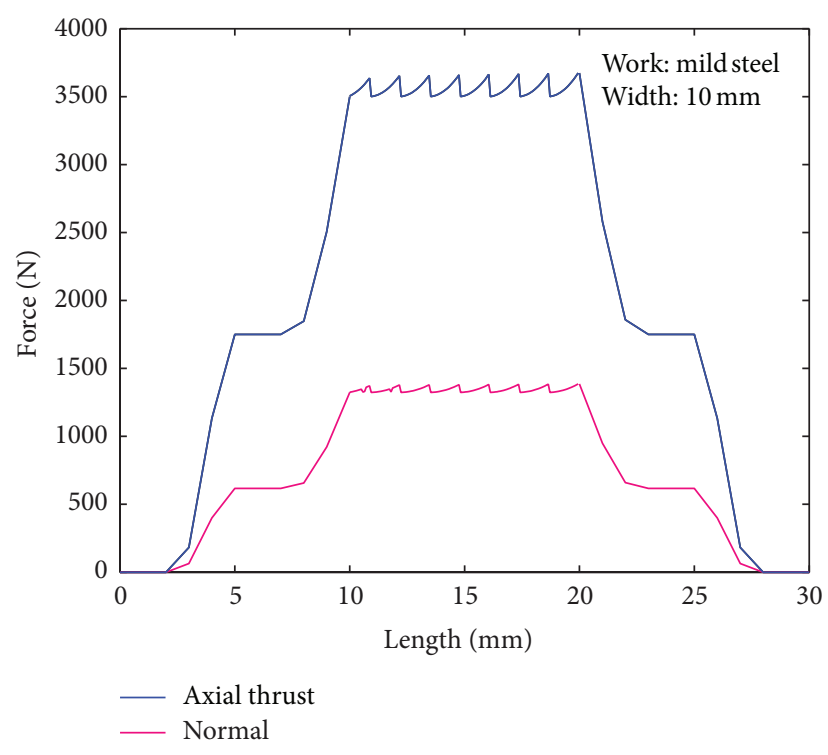

(a) Simulated cutting forces for $10 \mathrm{~mm}$ depth of cut

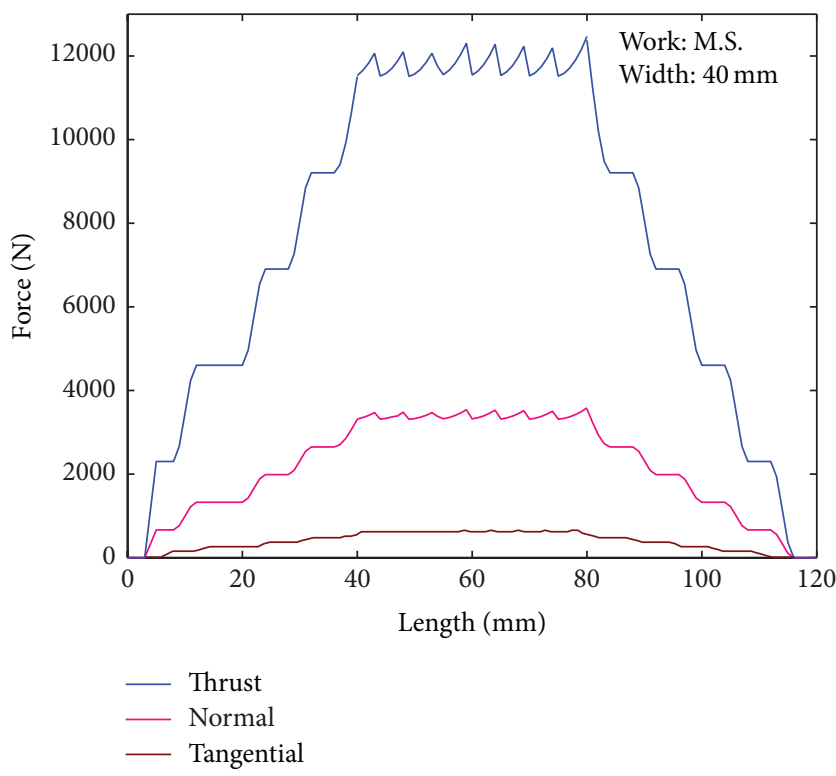

(b) Simulated cutting forces for $40 \mathrm{~mm}$ depth of cut

FIGURE 10: Simulated force values for mild steel work material of $10 \mathrm{~mm}$ and $40 \mathrm{~mm}$ depth.

and displays the output in the form of graphs or as digital displays and also has the provision for writing it to a text file. The data acquisition system includes National Instrument (NI)'s SCXI hardware unit, NI4472 card, and the API used is NI's LabVIEW 7.0 software. The number of specimens was prepared for different depth to perform the experiment. The experiments were conducted for different materials such as mild steel, aluminium and cast iron. The stored data was later processed to get graphical representation of cutting forces.

5.1. Technical Specifications of the Machine Tool. The specification of the machine tool is given in Table 4. It is a low capacity broaching machine with push type feed. 


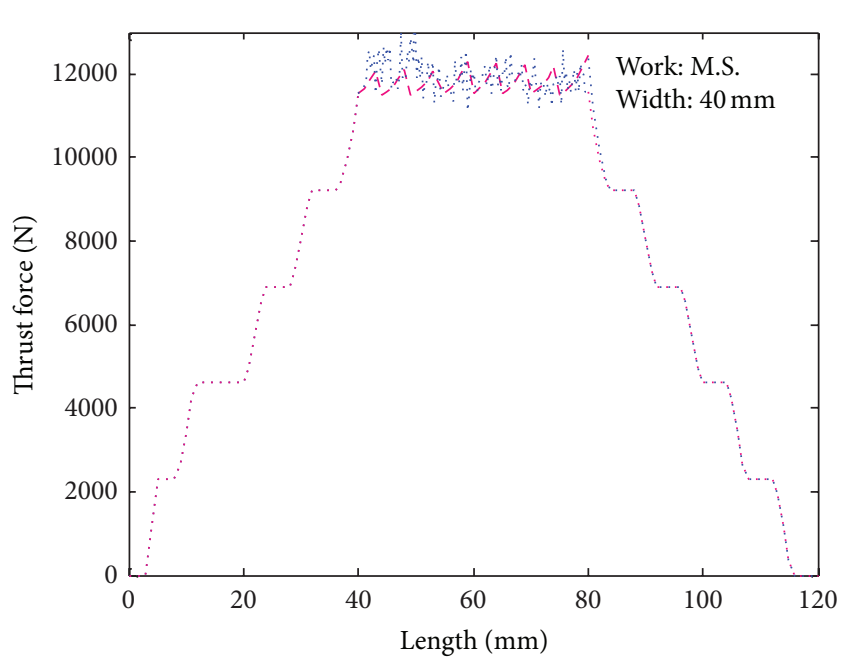

(a) Cutting forces in axial direction

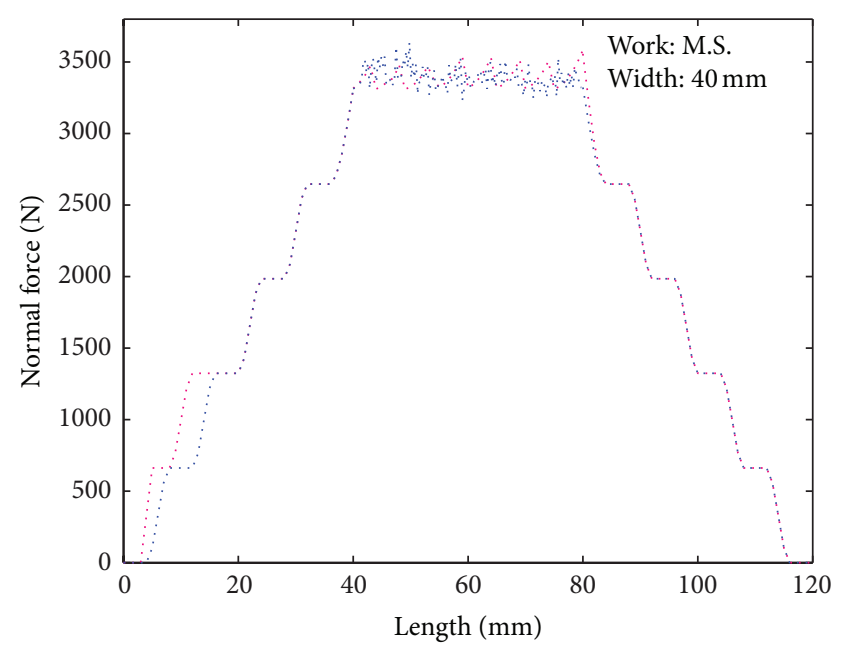

(b) Cutting forces in normal direction

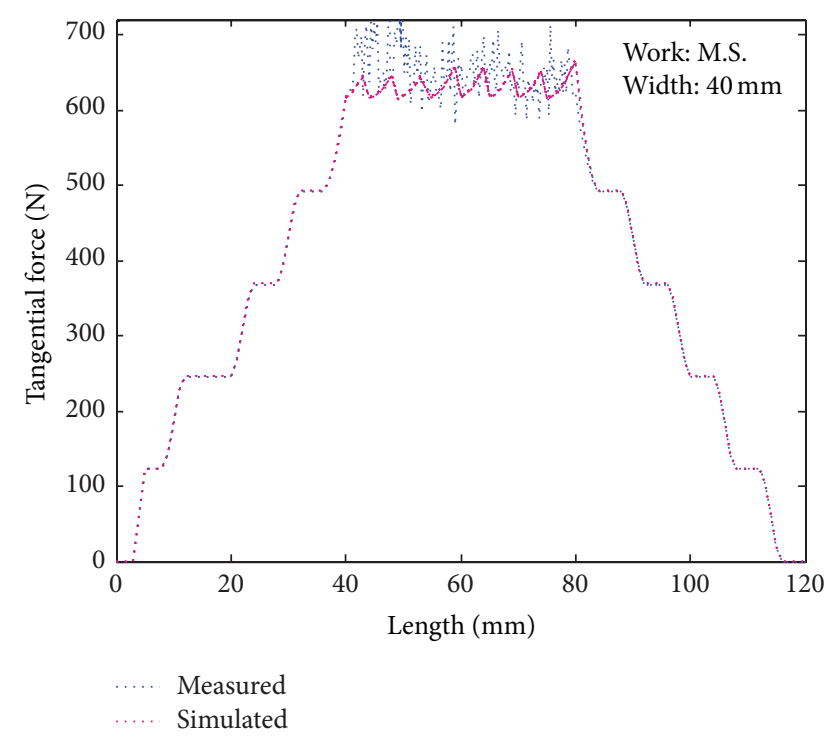

(c) Cutting forces in lateral direction

FIGURE 11: Comparison of measured and simulated force values during broaching operation on mild steel work.
TABLE 4: Technical specifications.

\begin{tabular}{lc}
\hline Maximum push load capacity & $5000 \mathrm{~kg}$ \\
Maximum stroke & $500 \mathrm{~mm}$ \\
Face plate dimension & $405 \times 210 \mathrm{~mm}$ \\
Slot dimension in face plate & $100 \mathrm{~mm}$ \\
Broaching speed & $1.5 \mathrm{~m} / \mathrm{min}$ \\
Return speed & $3 \mathrm{~m} / \mathrm{min}$ \\
Power of electric motor & $1.5 \mathrm{~kW} / 2 \mathrm{HP} / 1500 \mathrm{RPM}$ \\
\hline
\end{tabular}

The photograph of the accelerometer position on the machine tool is shown in Figure 8.

\section{Results and Discussions}

Figures 9(a) and 9(b) show the measured values of cutting forces acting on mild steel workpiece of $10 \mathrm{~mm}$ and $40 \mathrm{~mm}$ depth, respectively. The pattern of experimental result is closely in agreement with mechanistic model results in Figures 10(a) and 10(b). The percentage of error between experimental results and mechanistic model results is within $2 \%$.

Figures 11(a), 11(b), and 11(c) show the comparison of experimental results with simulated results for cutting force variation for a mild steel workpiece of $40 \mathrm{~mm}$ depth in axial, normal, and lateral directions. As height of the work piece increases, forces are also increasing and repeatedly in sinusoidal manner and come to zero as broach disengages with the work piece.

The experiment and simulated results shown in Figures 11(a), 11(b), and 11(c) confirm that axial force is very much higher than normal force for both $40 \mathrm{~mm}$ and $10 \mathrm{~mm}$ depth of mild steel work material. The force in the tangential direction is even smaller in comparison to the axial force.

\section{Conclusions}

This paper reports the dynamic force modeling of broaching process and validation of output with experimental results. A software has been developed to compute the dynamic forces using Matlab. Experiment has been carried out using a vertical broaching machine for the mild steel material of different depths. Experimental validations of the cutting forces are required to establish the prediction from the model so that the model is acceptable to the manufacturing industry. The work piece is the most complicated link of the machining system. The second validation deals with a case where a machine tool spindle is the weakest part of the system. The fixture of the work piece for the broaching was mounted such that feed direction becomes very compliant. Slots were provided on the fixture so that cutter can perform axis symmetry cutting. The position of the cutter also permits a proper pressing action on the fixture so that cutting process has effect on the overall stability of the cutting process.

The parameters which affect the cutting process are depth of cut, feed rate and cutter geometry. The feed rate, determines the axial chip load. Overall stability increases 
as the feed rate is increased. This is due to the fact that specific cutting energy constant decreases as a function of chip load. Stability in general is accountable for dynamics in the axial direction for broaching because the work piece and machine tool dynamics in axial direction are usually of order of magnitude stiffer than in the normal direction. The occurrence of the chatter predominant during the experiment is largely dependent on the material specific cutting energy constants since they determine the magnitude of the forces which present during machining. During broaching, the work holding fixture has an important role to play in controlling the force acting on the tool. Major force acting on the broaching tool is in axial direction.

All the factors discussed above that affect stability and dynamics of the structural system are influential. A good understanding of how the dynamics affect the overall stability can be helpful to assess the quality of the product. The dynamics variables include stiffness, damping, natural frequency, and mode cycles. Special care has to be taken to ensure that experimentally collected data is clear and accountable. The simulated and experimental results are presented graphically and are in close agreement. It is concluded that mechanistic model is suitable for determining cutting forces for broaching process.

\section{Nomenclature}

$\begin{array}{ll}A_{c}: & \text { Chip cross-section area } \\ a_{i}, b_{i}, c_{i}: & \text { Specific cutting energy constants } \\ F_{a}: & \text { Axial cutting force } \\ F_{t}: & \text { Tangential cutting force } \\ F_{n}: & \text { Normal cutting force } \\ K_{x}, K_{y}, K_{z}: & \text { Proportionality constants } \\ t_{c}: & \text { Chip thickness } \\ v_{c}: & \text { Cutting velocity } \\ \gamma_{a}: & \text { Rake angle. }\end{array}$

\section{Conflict of Interests}

The authors declare that there is no conflict of interests regarding the publication of this paper.

\section{Acknowledgments}

The authors would like to express their gratitude and sincere thanks to Professor Dr. Appu Kuttan, Director, MANIT, Bhopal (MP), for guidance, valuable help, enthusiastic attitude, and suggestions throughout the period and National Institute of Technology Karnataka (NITK) Surathkal, for providing necessary facilities to conduct experiments.

\section{References}

[1] E. Linsley Horace, Broaching Tooling and Practice, Industrial Press, 1961.

[2] C. Monday, Broaching, Machinery Publication, London, UK, 1960.

[3] J. W. Sutherland, E. J. Salisbury, and F. W. Hoge, "A model for the cutting force system in the gear broaching process,"
International Journal of Machine Tools and Manufacture, vol. 37, no. 10, pp. 1409-1421, 1997.

[4] V. S. Belov and S. M. Ivanov, "Factors affecting broaching condition and broach life," Journal of Stanki Instruments, vol. 45, pp. 31-33, 1974.

[5] E. Kuljanic, "Cutting force and surface roughness in broaching," Annual CIRP, vol. 24, no. 1, pp. 77-82, 1975.

[6] M. E. Merchant, "Mechanics of the metal cutting process. I. Orthogonal cutting and a type 2 chip," Journal of Applied Physics, vol. 16, no. 5, pp. 267-275, 1945.

[7] M. E. . Merchant, "Basic mechanics of the metal cutting process," Journal of Applied Mechanics, vol. 168, pp. 175-178, 1954.

[8] T. Tyan and W. H. Yang, "Analysis of orthogonal metal cutting processes," International Journal for Numerical Methods in Engineering, vol. 34, no. 1, pp. 365-389, 1992.

[9] V. Sajeev, L. Vijayraghavan, and U. R. K. Rao, "An analysis of the effect of burnishing in internal broaching," International Journal of Mechanical Engineering, vol. 28, pp. 163-173, 2000.

[10] D. A. Axinte and N. Gindy, "Tool condition monitoring in broaching," Journal of Wear, vol. 254, no. 3-4, pp. 370-382, 2003.

[11] B. Daniel Dallas, Tool and Manufacturing Engineers Handbook, 3rd edition, 2002.

[12] H. S. Kim and K. F. Ehmann, "A cutting force model for face milling operations," International Journal of Machine Tools and Manufacture, vol. 33, no. 5, pp. 651-673, 1993.

[13] H. J. Fu, R. E. DeVor, and S. G. Kapoor, "A mechanistic model for the prediction of the force system in face milling operations," Journal of Engineering for Industry, Transactions of the ASME, vol. 106, no. 1, pp. 81-88, 1984.

[14] E. Felder, P. Gillormini, L. Tronchet, and F. Leroy, "A comparative analysis of three machining process: broaching, tapping and slotting," etude DGRST Materiaux, vol. 80, pp. 512-513, 1982.

[15] S. G. Kapoor, R. E. DeVor, R. Zhu, R. Gajjela, G. Parakkal, and D. Smithey, "Development of mechanistic models for the prediction of machining performance: model building methodology," Machining Science and Technology, vol. 2, no. 2, pp. 213-238, 1998.

[16] S. Jayaram, S. G. Kapoor, and R. E. Devor, "Estimation of the specific cutting pressures for mechanistic cutting force models," International Journal of Machine Tools and Manufacture, vol. 41, no. 2, pp. 265-281, 2001.

[17] E. Usui, A. Hirota, and M. Masuko, "Analytical predictions of three dimensional cutting process-part I: basic cutting model an energy approach," Journal of Engineering for Industry, Transactions of the ASME, vol. 100, no. 2, pp. 222-228, 1978.

[18] W. J. Endres, R. E. DeVor, and S. G. Kapoor, "A dual mechanism approach to the prediction of machining forces," ASME Journal of Engineering For Industry, vol. 117, no. 4, pp. 526-533, 1999.

[19] J. A. Kir, D. K. Anand, and C. Mahindra, "Matrix representation and prediction of three dimensional cutting forces," ASME Journal of Engineering For Industry, vol. 99, pp. 822-828, 1978.

[20] F. Koenigsberger and J. Tlusty, Machine Tool Structures-Vol. 1: Stability against Chatter, Pergamon Press, 1967.

[21] P. Albrecht, "Dynamics of the metal cutting process," ASME Journal of Engineering for Industry, vol. 87, pp. 429-441, 1965.

[22] J. D. Smith and S. A. Tobias, "The dynamic cutting of metals," International Journal of Machine Tool Design and Research, vol. 1, no. 4, pp. 283-292, 1961. 
[23] D. A. Stephenson and S. M. Wu, "Computer models for the mechanics of three dimensional cutting process part 1: theory and numerical methods," ASME Journal of Engineering for Industry, vol. 110, no. 1, pp. 32-37, 1988.

[24] H. Q. Zheng, X. P. Li, Y. S. Wong, and A. Y. C. Nee, “Theoretical modelling and simulation of cutting forces in face milling with cutter runout," International Journal of Machine Tools and Manufacture, vol. 39, no. 12, pp. 2003-2018, 1999.

[25] J. A. Yang, V. Jaganathan, and R. Du, "A new dynamic model for drilling and reaming processes," International Journal of Machine Tools and Manufacture, vol. 42, no. 2, pp. 299-311, 2002. 

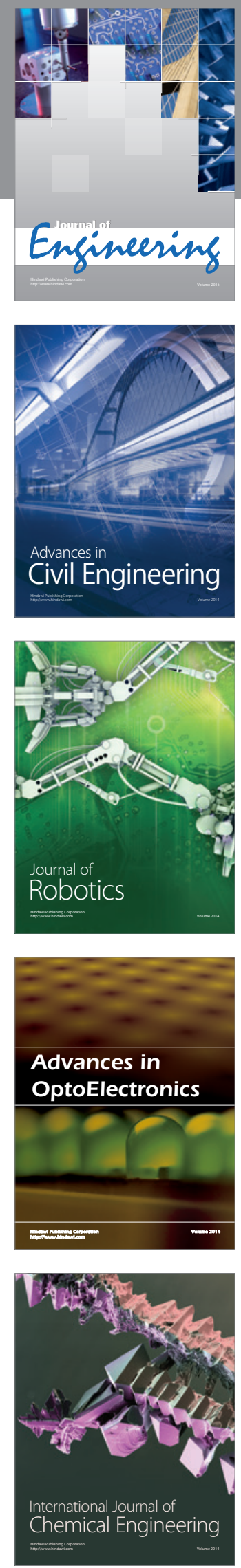

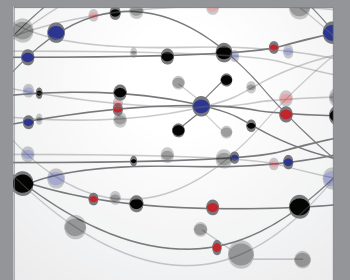

The Scientific World Journal
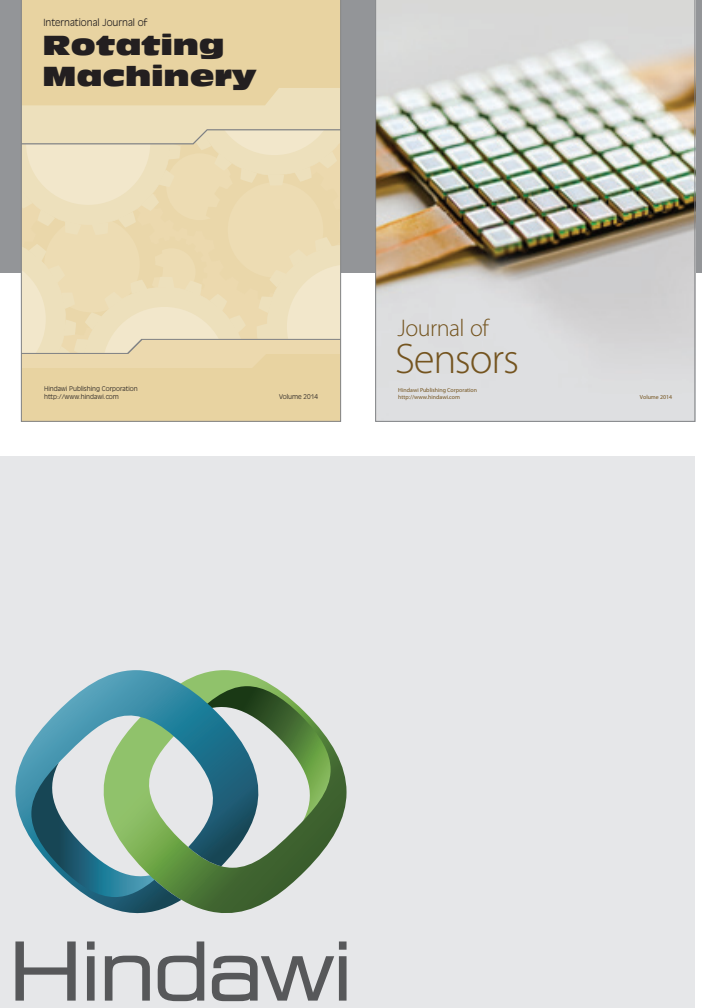

Submit your manuscripts at http://www.hindawi.com
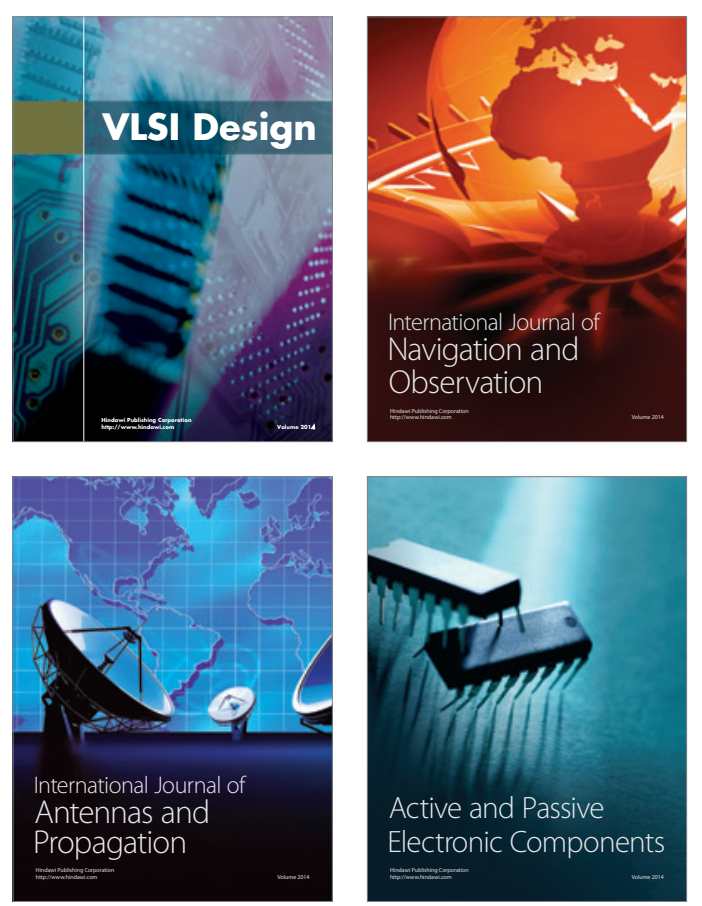
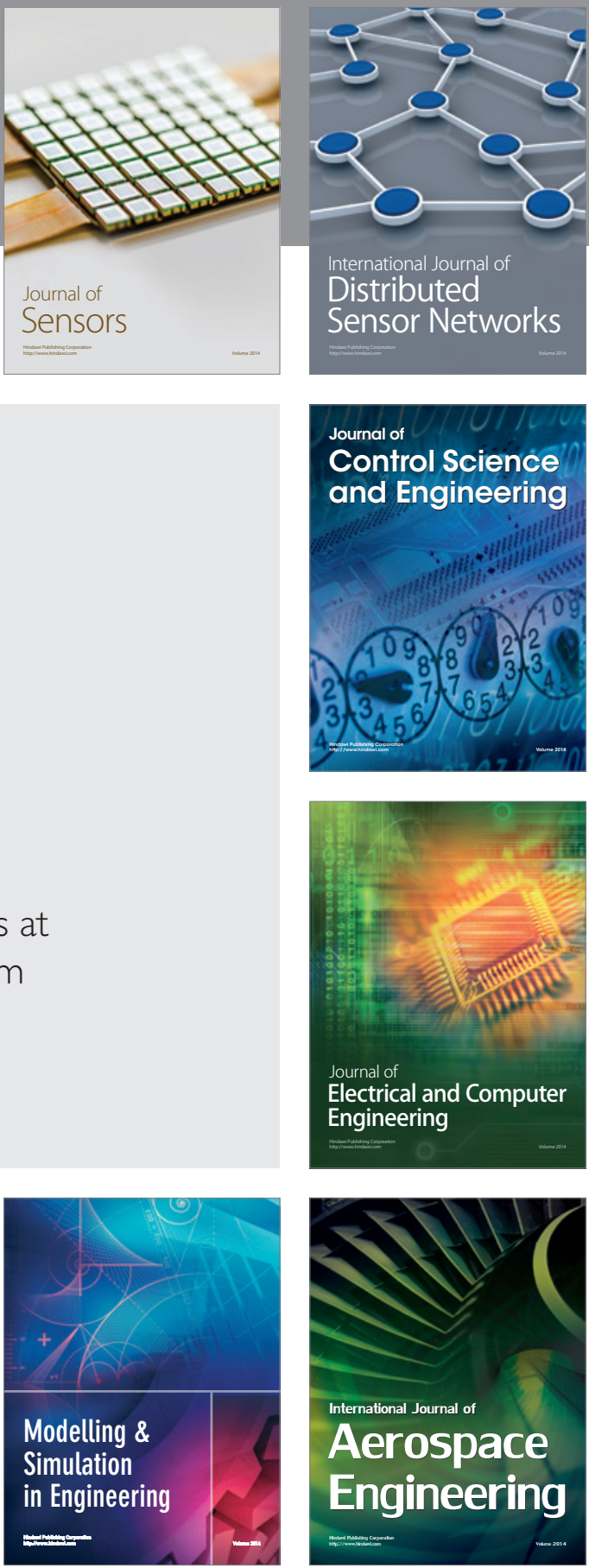

Journal of

Control Science

and Engineering
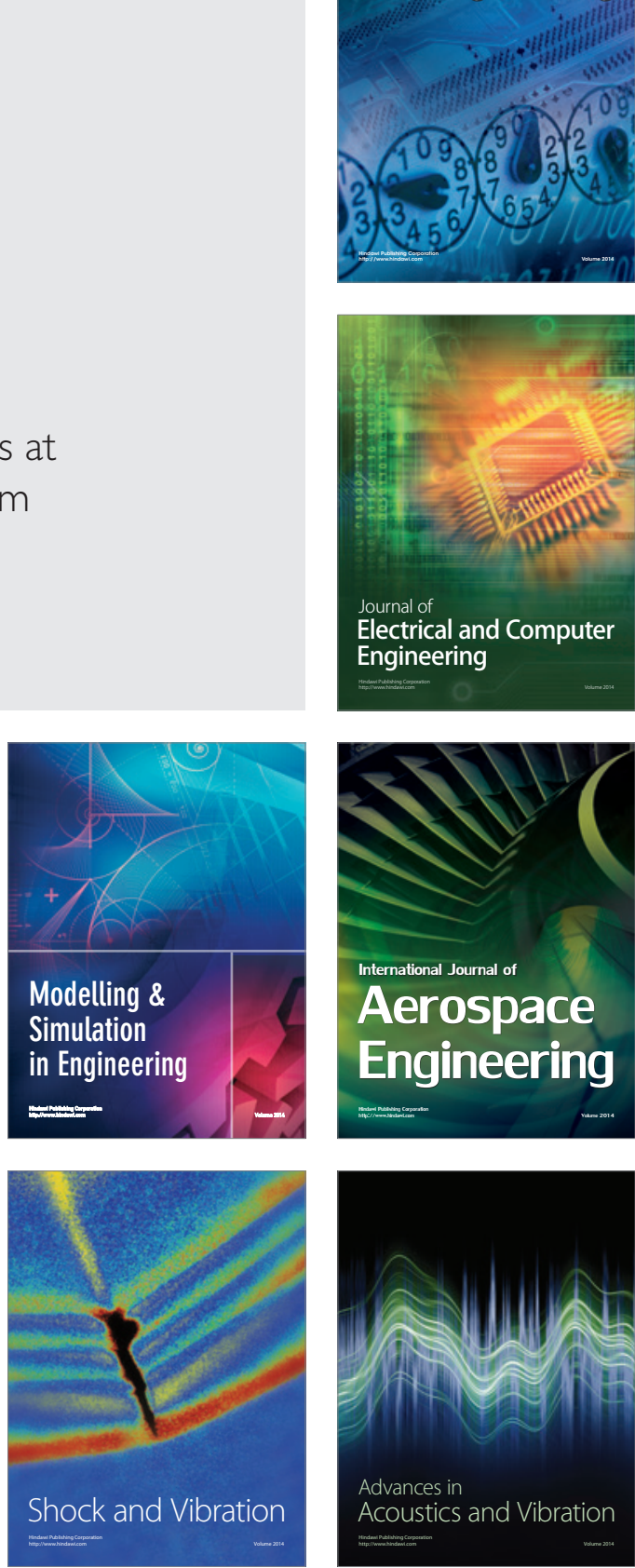